\title{
A PAISAGEM DAS ÁGUAS: A PERCEPÇÃO DOS USUÁRIOS COMO SUBSÍDIOS PARA A ELABORAÇÃO DE DIRETRIZES URBANÍSTICAS PARA AS MARGENS DOS RIOS POTI E PARNAÍBA E SEU ENTORNO (TERESINA-PI).
}

\author{
WATERSCAPE: USERS PERCEPTIONS AS A TOOL FOR THE DEVELOPMENT OF URBAN \\ GUIDELINES AT POTI AND PARNAIIBA'S RIVERBANKS AND SURROUNDINGS
}

\author{
MATOS, Karenina Cardoso \\ Arquiteta, professora mestre do Departamento de Construção Civil e Arquitetura, Centro de Tecnologia, \\ Universidade Federal do Piauí-CT/ UFPI. \\ E-mail: karenina@ufpi.br
}

VELOSO, Maísa Dutra

Arquiteta, professora doutora do PPGAU/UFRN - Programa de Pós-Graduação em Arquitetura e Urbanismo, Centro de Tecnologia.

E-mail:maisaveloso@vol.com.br

\section{RESUMO}

Partindo do pressuposto de que as águas têm grande poder de atração sobre as cidades e seus usuários, a pesquisa busca analisar as relações entre a paisagem das águas e Teresina, considerando quatro eixos conceituais: a paisagem das águas, a percepção dos usuários, os rios como linhas de força e a força de atração através dos elementos naturais, construídos e simbólicos da paisagem.

Os eixos estruturadores permitiram a leitura dos cenários, conforme a área delimitada que compreende os dois núcleos originais da cidade: o bairro Poti Velho e o centro de Teresina, de modo a descortinar aspectos visíveis e/ou não visíveis, valorizados ou não, com vistas a proporcionar subsídios para a formulação de diretrizes e intervenções de planejamento urbano de Teresina, especificamente na região ora em estudo.

Os elementos foram revelados de tal forma que caracterizam, hoje, a desvalorização dos rios diante das condições paisagísticas, geográficas, econômicas, culturais e ambientais analisadas; potencialidades existem, entraves e ameaças também são verificadas quanto à estrutura paisagística e à qualidade de vida da população ribeirinha; encontros e desencontros são percebidos na paisagem das águas. Entretanto, espera-se que este trabalho constitua um referencial a ser utilizado nas propostas de políticas públicas de urbanização da cidade viabilizando o reencontro de Teresina com seus rios a partir da percepção dos elementos que contextualizam a sustentabilidade adequada ao homem e ao ambiente em toda a sua plenitude de viver.

Palavras-chave: Paisagem, percepção, linha de força, força de atração.

\begin{abstract}
Assuming that waters have a strong power of attraction on the cities and their users, this research tries to assess the relation between the water landscape and Teresina city, regarding four conceptual axes: the water landscape, the perception of the users, the rivers as strength lines and the power of attraction througt natural, constructed and symbolic elements of the landcape.

The structuring axes enabled the reading of the sceneries, according to the delimited area which comprises two original nuclei of the city: bairro Poti Velho and the center of Teresina, in such a way as to show visible and/or non-visible, valued or nonvalued aspects, so as to provide subsidies for the designing of guidelines and interventions of urban planning of Teresina city, more particularly in the region being studied.

The elements were revealed, characterizing today the depreciation of the rivers within the landscaping, geographic, economical, cultural and environmental conditions analyzed; trere area potentialities; but there are also obstacles and threats to the landscaping structure and the quality of the riverside population;
\end{abstract}


convergences and divergences can be noticed in the water landscape. However, this work is expected to constitute a referential to be used in proposals of public policies of urbanization of this city, enabling Teresina to "meet" its rivers again from the perception of the elements contextualizing the suitable sustainability for the man and for the environment in all regards of life.

\section{Key words: Landscape, perception, strength lined, power of attraction.}

\section{Introdução}

Historicamente, as águas sempre exerceram poder de atração sobre as cidades e seus usuários. A sede das cidades era geralmente fundada no litoral ou nas margens de rios ou lagoas. Ainda que a paisagem das águas fosse posteriormente esquecida, o marco inicial das cidades permanece, de certa forma, a elas vinculado. Mas, em muitos casos, esses locais antes privilegiados e, na maioria das vezes, estruturadores da ocupação e do crescimento da cidade, agora são atualmente pouco valorizados e/ou percebidos. Esse é o caso de Teresina, no estado do Piauí, cuja origem está diretamente vinculada à presença dos rios que a cortam (Figura 1).

A escolha do tema sobre a paisagem das águas e seus elementos de composição foi decorrência da constatação da importância da paisagem dos rios Poti e Parnaíba para Teresina. São eles os dois rios urbanos que cortam e delimitam a cidade, passando por grande parte dos bairros e participando, ora ativamente, ora passivamente, do cotidiano da cidade. Também foi fator relevante para a escolha do tema, a carência de estudos acadêmicos sobre a importância desses rios para o planejamento urbano de Teresina, apesar do surgimento recente de planos (estratégias) e projetos (construções) isolados de atuação do poder público e da iniciativa privada, como também, intervenções não planejadas (até mesmo irregulares) promovidas pela própria população ribeirinha residente na área.

Ressalte-se que, nesse trabalho, a paisagem das águas não se refere aos rios Poti e Parnaíba como principal ou único elemento a ser estudado, mas sim, à paisagem cultural das águas, resultado das "inter-relações entre as intenções humanas e os processos naturais" (COSTA; MONTEIRO, 2002, p. 291). Ou seja, a paisagem das águas se refere à "inserção paisagística das águas nas cidades" (COSTA; MONTEIRO, 2002, p. 291). Nesse contexto, a pesquisa pretende dar visibilidade aos rios Poti e Parnaíba e integrá-los aos outros elementos da paisagem como premissas do projeto urbano. Assim, o objeto do estudo não é o rio, mas a paisagem ribeirinha; ou melhor, é o estudo da paisagem na sua complexidade natural-construída-símbólica, considerando a relevância dos processos naturais, mas reconhecendo o seu valor como paisagem cultural.

Nas últimas décadas, a ocupação das margens desses rios não se deu de forma articulada e equilibrada, e sim, ameaçando o meio ambiente e desvalorizando o potencial paisagístico do local (atualmente, pouco reconhecido e explorado). Pode-se dizer que, a cidade, hoje, "dá as costas para seus rios": a população pouco percebe e/ou valoriza esses elementos fundamentais da paisagem local e os rios, geralmente, não são devidamente considerados no processo de planejamento urbano da cidade.

Assim, a percepção dos usuários, sejam permanentes ou transitórios, é importante para uma intervenção integrada na cidade, pois são eles que indicam as formas pelas quais aquele ambiente pode ser interpretado para ser valorizado e vivido de maneira mais intensa. Segundo Machado (1999, p. 99):

"É inegável que há uma profunda diferença entre cenário descrito e estudado, e um cenário experienciado e vivido. É a familiaridade em relação a tudo o que existe na paisagem que the confere um significado especial; onde os habitantes vivem, se movimentam e se relacionam entre si e com a paisagem." 


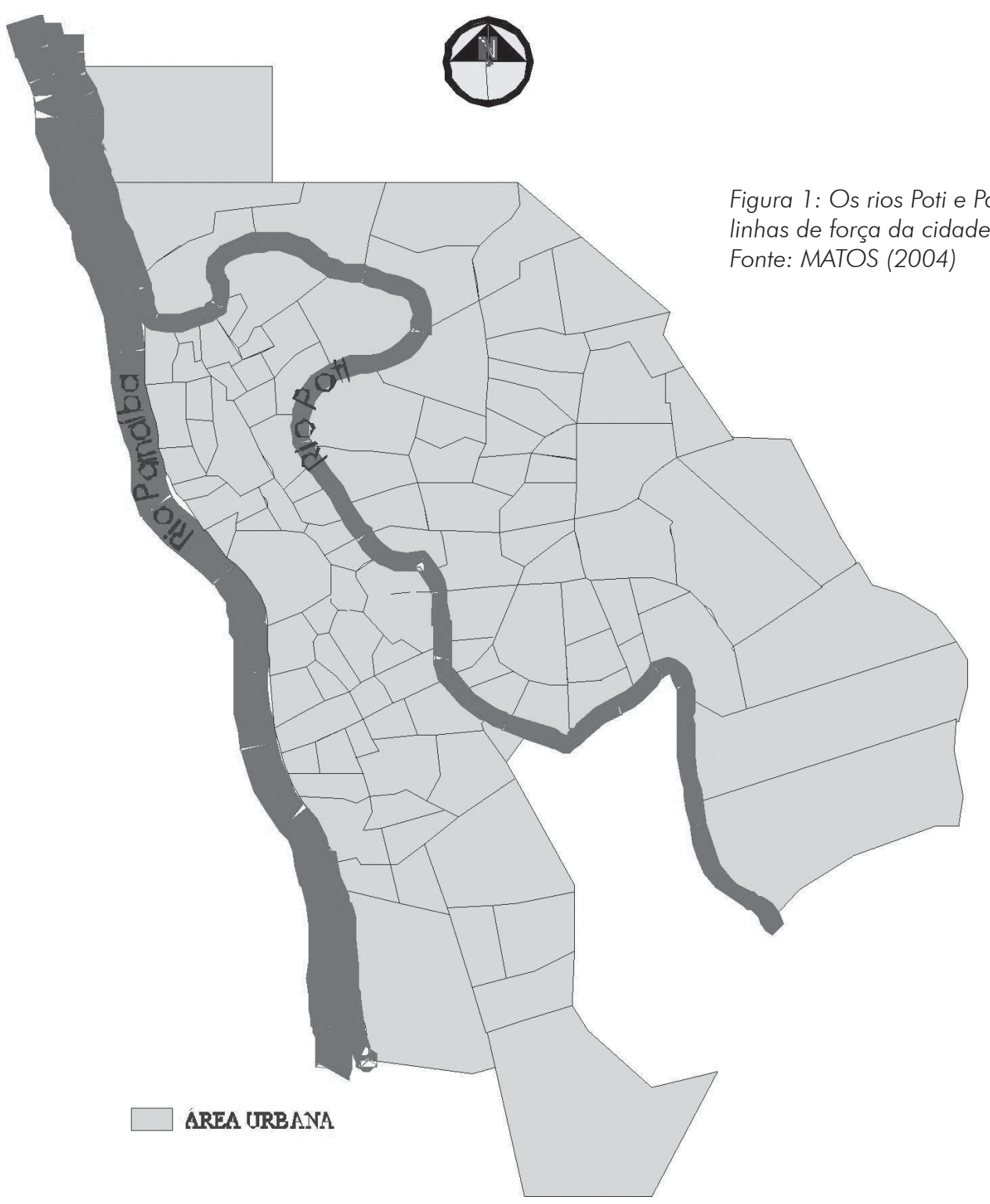

Nesse sentido, os moradores e as pessoas que trabalham na região tendem a perceber a paisagem de forma diferenciada daqueles que esporadicamente vão ao local. Valorizar o que é percebido, feito ou utilizado no dia-a-dia é tão importante quando a descoberta de outros elementos que, a princípio, não são tão destacados por aqueles que têm seu contato diário. $\mathrm{Na}$ realidade, são percepções diferentes que refletem o grau de expectativas de cada categoria, chamando atenção daquilo que já faz parte do cotidiano ou daquilo que é novidade.

Considerando a importância dos rios Poti e Parnaíba para Teresina (como linhas de força da paisagem) e considerando a importância da percepção dos usuários para a formulação de estratégias de planejamento urbano, a pesquisa desenvolveu-se tendo como base as seguintes perguntas de partida:

Por que a percepção dos usuários não é considerada para a conservação e valorização da paisagem no planejamento urbano? É de fato possível integrar a percepção dos usuários nos processos de planejamento urbano e desenho urbano? Se afirmativo, quais os benefícios e quais os obstáculos/limites de se considerar a percepção dos usuários nesses processos?

Os rios Poti e Parnaíba exercem para as áreas ribeirinhas de Teresina a função de linha de força da paisagem? De que maneira os rios, enquanto elementos da paisagem, são percebidos em 
Teresina pelos usuários, pelo poder público (quando formula o planejamento urbano) e pelos arquitetos e urbanistas (quando estudam e planejam o desenvolvimento urbano)?

Será que os rios Poti e Parnaíba exercem a força de atração? Que aspectos da paisagem dos rios são considerados e/ou valorizados?

Para responder a essas indagações, e considerando o objeto demarcado, o estudo tem o seguinte objetivo principal: a partir da investigação sobre as intervenções localizadas entre os bairros Poti Velho e Centro da cidade feitas pelo poder público, pela iniciativa privada e pela população, e, principalmente, com base na percepção e na avaliação dos usuários da área, identificar os principais problemas e potencialidades da paisagem das margens dos rios Poti e Parnaíba, de modo a fornecer subsídios/diretrizes para projetos de intervenções no local, que visem reintegrá-los à imagem (positiva) da cidade. Implicitamente, o trabalho é uma reflexão acerca da importância da paisagem dos rios para o planejamento urbano da cidade de Teresina.

"Porém, se compreendermos os princípios que fundamentam o comportamento das cidades, poderemos aproveitar-nos de vantagens e pontos fortes potenciais, em vez de atuarmos contrariamente a eles. Primeiro precisamos definir que resultados genéricos desejamos - o que saberemos ao descobrir como transcorre a vida na cidade." (JACOBS, 2000, p. 153)

Assim, seguindo a mesma idéia de Jacobs (2000, p.153), para alcançar o objetivo principal, é necessário alcançar dois objetivos intermediários: (a) considerando os rios Poti e Parnaíba linhas de força da paisagem, fazer a leitura da paisagem "do modo como percebem seus habitantes" (LYNCH, 1997, p. 3), isto é, identificar os principais elementos da paisagem a partir da percepção dos usuários (paisagem revelada); e (b) considerando a paisagem revelada e a força de atração dos elementos da paisagem ribeirinha, "ver as formas ocultas na vasta extensão das nossas cidades" (LYNCH, 1997, p. 14), isto é, descortinar a paisagem complexa, interpretando a leitura aparente dando-lhe rigor e clareza, explicando as inter-relações dos elementos da paisagem entre si e dos elementos da paisagem com os usuários (paisagem oculta).

\section{Eixos conceituais}

A pesquisa foi estruturada a partir de quatro eixos conceituais: paisagem, percepção, linha de força e força de atração.

Sobre os conceitos de paisagem e de percepção há uma vasta literatura. Na presente pesquisa, considera-se que a distinção entre esses dois conceitos é meramente didática, pois a paisagem necessariamente precisa ser percebida, assim como a percepção é sempre o entendimento de algo (natural ou construído); ou seja, a paisagem é sempre a imagem de algo que foi percebido. Partindo desse ponto, a indissociabilidade entre percepção e paisagem, deve-se, então, considerar a paisagem, tanto em seus aspectos subjetivos, como objetivos. A paisagem pode ser objeto de várias percepções e, em especial, daquelas relacionadas aos usuários, geralmente esquecidas no momento da formulação do planejamento urbano.

Como instrumento para observação dos elementos da paisagem, fez-se uso do conceito de linha de força, elaborado por Cullen (1993), adotado no Brasil por Sá Carneiro e Mesquita (2000).

Por fim, nessa pesquisa, desenvolveu-se a idéia de força de atração; segundo o qual um determinado elemento da paisagem serve como magneto que atrai ou repele outros elementos da paisagem, conforme o caso.

\section{Delimitação do objeto}

O presente trabalho tem como objeto a paisagem das águas, a partir, sobretudo, da percepção dos usuários da cidade. Para tanto, partiu-se de três recortes metodológicos: (a) um recorte espacial, (b) um recorte temático; e (c) um recorte teórico metodológico. 
No recorte espacial, a área de estudo compreende desde a ponte Mariano Gayoso², próxima à confluência dos rios Poti e Parnaíba, estendendo-se por toda a faixa ribeirinha até a ponte da Amizade ${ }^{3}$, no limite sul do núcleo original da cidade. Ela abrange, assim, os dois núcleos originais da cidade: a barra do Poti ${ }^{4}$, no início do século XVIII, e a chapada do Corisco ${ }^{5}$, sede da capital da província desde $1852^{6}$. A antiga sede da Vila do Poti estava próximo à confluência dos rios Poti e Parnaíba (na barra do Poti); mas, para evitar as enchentes, ela foi transferida para outro local mais alto (na chapada do Corisco), ainda nas margens do rio Parnaíba.

Nesse trecho em estudo, os rios Poti e Parnaíba são acompanhados pela rua Des. Flávio Furtado e pelas avenidas Boa Esperança e Maranhão (Quadro 1). As três vias seguem o mesmo prolongamento (sempre margeando os rios), mudando de denominação à medida que percorrem os diferentes bairros da área demarcada (ou seja, as três vias correspondem a apenas uma linha viária "repartida" em três trechos com denominações diferentes).

\begin{tabular}{|l|l|l|l|}
\hline & \multicolumn{1}{|c|}{ Cenário } & \multicolumn{1}{c|}{ Cenário } & \multicolumn{1}{c|}{ Cenário } \\
\hline $\begin{array}{l}\text { Síntese das principais } \\
\text { características }\end{array}$ & Cultural e gastronômico & Ambiental e sustentável & Histórico e comercial \\
\hline Principal via & Rua Flávio Furtado & Avenida Boa Esperança & Avenida Maranhão \\
\hline Limites & $\begin{array}{l}\text { Ponte Mariano Gayoso e } \\
\text { parque ambiental Encon- } \\
\text { tro dos Rios }\end{array}$ & $\begin{array}{l}\text { Parque Ambiental En- } \\
\text { contro dos Rios e Parque } \\
\text { Ambiental Rio Parnaíba }\end{array}$ & $\begin{array}{l}\text { Parque Ambiental Rio } \\
\text { Parnaíba e Ponte da } \\
\text { Amizade }\end{array}$ \\
\hline $\begin{array}{l}\text { Bairros (unidade territorial- } \\
\text { administrativa da prefeitura) }\end{array}$ & Poti Velho e Olarias & $\begin{array}{l}\text { Olarias, São Joaquim, } \\
\text { Matadouro }\end{array}$ & $\begin{array}{l}\text { Acarape, Pirajá, Matinha } \\
\text { e Centro }\end{array}$ \\
\hline Rios & Rio Poti & Rio Parnaíba & Rio Parnaíba \\
\hline
\end{tabular}

Quadro 1: Síntese dos cenários

No recorte temático, foram estudadas as relações entre paisagem e usuários da cidade, a partir da percepção destes últimos. No recorte teórico, foram utilizados como referências principais os estudos de Lynch (1997), Culen (1983) e Tuan (1980), e, em especial, os conceitos de linha de força e de força de atração da paisagem.

Para o desenvolvimento desse trabalho, fez-se uso de técnicas de pesquisa bibliográfica, documental e empírica. Na pesquisa empírica, foram feitas visitas e observações in loco, bem como, aplicados formulários e realizadas entrevistas a diversos usuários da área em estudo, seguindo roteiros direcionados. A pesquisa empírica objetivou identificar a percepção que diversos segmentos da sociedade tinham da paisagem da área demarcada, particularmente a percepção feita pelos usuários.

A leitura dos cenários foi feita, a partir da percepção dos usuários quanto ao seu cotidiano na vivência do espaço delimitado para essa pesquisa, bem como, da percepção da pesquisadora na verificação dos elementos quando compõem a linha de força do respectivo espaço, o que se denominará de paisagem revelada. Num segundo momento, a leitura foi feita pelo observador (pesquisador), considerando a paisagem oculta, aquela direcionada para o objetivo especifico, que é a interpretação dos elementos identificados na paisagem e suas inter-relações quanto ao poder de atração e repulsão dos rios e quanto aos elementos entre si. Essa leitura, fundamental para a pesquisa, visou, sobretudo, a necessidade de se transferir "o olhar" para a manutenção, valorização e preservação da área, a fim de que essas paisagens sejam descortinadas de forma planejada e organizada.

\section{Um olhar para os mapas e a legibilidade da cidade}

Existem várias maneiras de começar a conhecer as cidades, uma delas é através dos mapas. Os mapas são uma fonte de comunicação visual capaz de representar idéias através de desenhos, símbolos e letras. 
Olhando o mapa de Teresina e percorrendo a cidade, percebe-se que os rios são elementos marcantes da cidade, ora como marco simbólico, ora como limite $^{8}$, ora como via ${ }^{9}$ e ora como pontos nodais ${ }^{10}$. Segundo Lynch (1997, p. 134), os elementos configurados do espaço permitem ao observador uma sensação de segurança, pois precisamos "de um ambiente que não seja simplesmente organizado, mas também poético e simbólico". A legibilidade é um dos principais indicadores da boa imagem da cidade e conseqüentemente da valorização dos rios e seu entorno.

Os rios para serem percebidos precisam estar bem definidos tanto em planta (mapas) quanto na paisagem da cidade. Torná-los visível é fundamental para a auto-estima da cidade e preservação dos recursos hídricos, bem como seu aproveitamento para utilização do lazer contemplativo, esportivo, pesca, etc.

Os rios são considerados aqui como o elemento visual e paisagístico que permite e facilita a leitura da cidade, na medida que, a sua linha atravessa a cidade, e que atraiu e atrai outros elementos simbólicos, construídos e naturais.

Considerar a margem dos rios urbanos como espaço livre e público e inclúi-la no planejamento urbano da cidade são iniciativas que devem ser tomadas para que ocorra a requalificação urbana desses espaços, onde a legibilidade (LYNCH, 1997) e a linha de força (CULLEN,1993; SÁ CARNEIRO; MESQUITA, 2000) possam ajudar no exercício de se tentar compreender as complexidades das paisagens da cidade.

O estudo sobre os rios em Teresina como linha de força na paisagem poderá transformar esse elemento natural em elemento indispensável para o planejamento urbano da cidade, em um elemento legível, bem como influenciar na auto-estima da população e na imagem da cidade.

Outros fatores, conforme mostra Calvino (1990), ajudam a entender a cidade e suas paisagens, na medida, que são reconhecidos seus valores: históricos, econômicos, ambientais, culturais, paisagístico e social. Essa área permite passear por Teresina e conhecer um pouco de suas particularidades entendendo que:

"a cidade não conta o seu passado, ela o contém como as linhas da mão, escrito nos ângulos das ruas, nas grades das janelas, nos corrimãos das escadas, nas antenas dos pára- raios, nos mastros das bandeiras, cada segmento riscado por arranhões, serradeiras, entalhes, enfoladuras."(CALVINO, 1990, p. 14-15).

\section{Conclusão}

A partir do olhar sobre o encontro dos rios Poti e Parnaíba com a cidade, algumas causas de desencontros foram observadas, no caminho da paisagem das águas. Com base nas análises, também foram identificados potenciais que, se devidamente explorados, podem levar ao reencontro de Teresina com seus rios.

Assim, essa pesquisa procurou identificar a importância da paisagem das águas para Teresina, a partir da análise realizada no trecho compreendido entre dois marcos construídos e simbólicos - a Ponte Mariano Gayoso e a Ponte da Amizade. Tomou-se como ponto de partida o conceito de linha de força e os rios Poti e Parnaíba foram identificados na paisagem de Teresina como marco simbólico e estrutural da paisagem. Também foi utilizado o conceito de força de atração que estabelece, na paisagem das águas, relações de atração e repulsão entre os elementos naturais, construídos e simbólicos, como os rios, as lagoas, os parques ambientais, as praças, as oficinas cerâmicas, as olarias, os cais, as pontes, o aqueduto, as edificações históricas, as ocupações em área de risco, o comércio, as enchentes, etc.

Para as análises, fez-se uso de duas estratégias para leitura da paisagem: a paisagem revelada e a paisagem oculta. Assim, considerando os resultados das análises dos três cenários, percebe- 
se que a "riqueza" paisagística de cada bairro estudado encontra-se principalmente na margem dos rios. Apesar das diferenças de atividades e de usos, a leitura indica que nos três cenários não são valorizados os rios Poti e Parnaíba, como elementos de planejamento urbano ou paisagístico. Os rios são percebidos como elementos isolados, ora como fator atraente (olarias, cerâmicas, parques ambientais e hortas comunitárias), ora como fator de repulsão (enchentes e polvição). Ressalta-se, apenas, a valorização dada aos rios na escolha do local para o desenvolvimento da cidade e do primeiro plano urbanístico, que os tinha como limites físicos para o traçado da nova cidade (1852). Faz-se, então, necessária a implementação de novas medidas, visando a reintegração dos rios à cidade.

Hoje, entretanto, os rios não representam a mesma força no processo de planejamento urbano, quando se observam as intervenções voltadas, especificamente, para as questões de transportes (linha do metrô, pontes e vias), sem considerar os aspectos de identidade, valorização e integração dos rios. As necessidades impõem os serviços a serem desenvolvidos pela cidade, entretanto, as propostas devem ser contextualizadas, de modo que os elementos identificadores de um lugar não percam a sua referência. A esse respeito exemplifica-se a integração harmônica da Ponte Metálica, da avenida Maranhão e do rio Parnaíba na mesma paisagem. Em contraste com as intervenções recentes, como os projetos da Ponte da Amizade e da linha férrea do metrô, que comprometem a visão da paisagem das águas.

Assim, em síntese, na área estudada percebem-se os seguintes problemas: (a) falta legibilidade da paisagem das águas; (b) o descaso com a paisagem natural resulta em degradação ambiental; (c) os efeitos das calamidades naturais, como as enchentes não são eficazmente controladas e prevenidas; (d) as regiões ribeirinhas carecem de espaços livres públicos adequados para o lazer e para a convivência; (e) a saturação do sistema viário, bem como a desorganização do comércio informal no centro; ( $f$ ) a falta de condições de sustentabilidade ambiental, econômica e social nos cenários I e II; (g) o descaso com a preservação do patrimônio histórico e cultural.

O estudo também permitiu a identificação das principais necessidades e potencialidades da área: (a) a consideração da percepção dos usuários pode levar à formulação de políticas urbanas e sociais mais justas e eficientes; (b) o uso das praças, dos parques ambientais e das lagoas como espaços livres públicos, integrados com a paisagem dos rios, servindo não só como espaços de lazer e de convivência, como também elementos de redução dos efeitos do forte calor que predomina na cidade; (c) uma infra-estrutura viária como mecanismo de eliminar os entraves e as limitações das vias urbanas no escoamento de veículos, quer nas necessidades da própria zona, quer com a construção de vias expressas que permitam a interligação mais rápida da região central com outras zonas da cidade, considerando a paisagem de cada cenário; (d) o investimento nas atividades oleiras, cerâmicas, pesqueiras, gastronômicas, hortícula e turística, direcionadas para resultados ambientais, econômicos e sociais; (e) a revitalização do centro da cidade; (f) o resgate da história e a promoção dos valores culturais, contribuindo para o desenvolvimento da auto-estima dos cidadãos e sua re(identificação) com os elementos que deram origem à cidade.

Para solucionar esses problemas e para desenvolver as potencialidades da paisagem das águas, - Plano de Desenvolvimento Sustentável de Teresina (Agenda 2015) reuniu vários projetos. Destacam-se: (a) o Projeto Lagoas do Norte, que beneficiará os cenários I e II, com infra-estrutura básica de lazer e melhoria nas condições de transporte, saneamento básico e habitação; trata-se de um projeto de relevante impacto ambiental; (b) o Projeto Revitalização do Centro (dirigido para o cenário III); e (c) o Projeto Parques Ambientais, que pretende preservar a margem dos rios, ao tempo em que promove atividades de lazer; funcionam, pois, como atrativos de forma a propiciar o olhar para os rios, percebendo-os e valorizando-os.

Desta forma, considerando os resultados apresentados, e as indicações dos projetos citados, as sugestões a seguir são propostas de modo a oferecer subsídios para as diretrizes de intervenção na área estudada: 
Cenário I, enfatizar a integração da história, cultura, religiosidade, pesca e cerâmica à paisagem das águas, criando: (a) museu aberto das origens; (b) passarela dos ceramistas; (c) corredor do pescado; e (d) jardim das esculturas.

Cenário II, enfatizar o desenvolvimento das atividades econômicas integradas à preservação ambiental na margem do rio Parnaíba e da lagoa dos Oleiros de forma sustentável, criando: (a) pátio dos oleiros; (b) corredor do pescado; e (c) áreas de lazer em substituição às ocupações de moradias em áreas de risco. É de real importância a promoção da educação e da consciência ambiental, do turismo e do lazer.

Cenário III, enfatizar a revitalização do centro histórico e comercial de forma integrada à paisagem do rio Parnaíba, com: (a) ordenação do centro histórico e comercial; (b) revitalização das praças como espaços de lazer; e (c) o resgate de marcos históricos e arquitetônicos.

Por fim, considerando todo o contexto da paisagem das águas, três aspectos devem ser enfatizados de modo a promover o desenvolvimento econômico e social da área: (a) dar legibilidade à paisagem dos rios; (b) oferecer proteção às áreas ribeirinhas contra enchentes; e (c) planejar uma malha urbana integrada e equilibrada, articulando todos os cenários. Para tais promoções sugere-se a criação de: ( $a^{1)}$ passeios rodoviários e fluvial; $\left(b^{1}\right)$ a ampliação do dique; $\left(b^{2}\right)$ a ampliação do sistema de drenagem; e $\left(b^{3}\right)$ a promoção da ocupação sustentável das áreas de risco.

As intervenções devem ser precedidas de uma leitura adequada da paisagem onde se pretende intervir, considerando a diversidade de percepções dos atores envolvidos. Deve-se considerar, também, a linha de força como elemento referencial da paisagem. Para o planejamento deve-se integrar adequadamente os elementos naturais, construídos e simbólicos, considerando sempre a força de atração entre esses elementos. $E$ isto deve ser feito sempre com muito cuidado, pois toda intervenção é modificadora, e, uma vez materializada no espaço, tem um certo poder de permanência.

É, então, a capacidade de perceber elementos constitutivos da paisagem que favorece a transformação desses elementos em marcos referenciais, caracterizadores de uma cidade. No caso de Teresina, a busca desses marcos pode conduzir ao reencontro dos rios, com os seus usuários e as suas inter-relações com a paisagem, pois somente quando as potencialidades do lugar forem descortinadas, conhecidas e declaradas, os planos urbanísticos poderão dar a sustentabilidade adequada ao contexto da cidade, transformando a imagem (negativa) de uma cidade fortemente caracterizada pelo calor para a imagem (positiva) de uma cidade "mesopotâmica", vislumbrada pela beleza da paisagem de suas águas.

\section{Notas}

(1) Formam a paisagem das águas, além dos rios Poti e Parnaíba, um complexo de lagoas na zona norte e os espelhos d'água das praças Marechal Deodoro e Da Costa e Silva e dos outros elementos a eles relacionados.

(2) A denominação oficial da Ponte Mariano Gayoso é Ponte Mariano Gayoso Castelo Branco. Neste trabalho, adotarse-á a denominação não-oficial por ser a mais difundida.

(3) A denominação oficial da Ponte da Amizade é Ponte José Sarney. Neste trabalho, adotar-se-á a denominação nãooficial por ser a mais difundida.

(4) Próximo à Ponte Mariano Gayoso.

(5) Próximo à Ponte da Amizade.

(6) O povoamento da região iniciou-se no século XVIII. Em 1832, na barra do Poti, o povoado foi elevado à condição de vila (vila do Poti). Em 1851 a sede da vila do Poti foi transferida da barra do Poti para chapada do Corisco. Em 1852 a vila do Poti foi elevada à condição de capital da província, sendo denominada Teresina.

(7) Marcos são "usados como indicadores de identidade, ou até de estrutura, e parecem tornar-se mais confiável à medida que o trajeto vai ficando cada vez mais conhecido" (LYNCH, 1997, p. 53). 
(8) Limites são "barreiras mais ou menos penetráveis que separam uma região da outra, mas também podem ser costuras, linhas ao longo das quais duas regiões se relacionam e se encontram" (LYNCH, 1997, p. 52).

(9) Vias são "os canais de circulação ao longo dos quais o observador se locomove de modo habitual, ocasional ou potencial" (LYNCH, 1997, p. 52).

10) "Pontos nodais são pontos, lugares estratégicos de uma cidade através dos quais o observador pode entrar, são os focos intensivos para os quais ou a partir dos quais ele se locomove" (LYNCH, 1997, p. 52).

\section{Bibliografia}

CALVINO, Italo. As cidades invisíveis. Tradução de Diogo Mainardi. São Paulo: Companhia das Letras, 1990.

COSTA, Lucia M.; MONTEIRO, Patrícia Maya. Rios urbanos e valores ambientais. In: DEL RIO, Vicente; DUARTE, Cristiane Rose; RHEINGANTZ, Paulo Afonso (Org.). Projeto do lugar: Colaboração entre psicologia, arquitetura e urbanismo. Rio de Janeiro: Contra Capa Livraria/PROARQ, 2002.

CULLEN, Gordon. Paisagem urbana. Lisboa: Edições 70, 1983.

JACOBS, Jane. Morte e vida de grandes cidades. São Paulo: Martins Fontes, 2000.

LYNCH, Kelvin. A imagem da cidade. São Paulo: Martins Fontes, 1997.

MACHADO, Lucy Marion C. P. Paisagem valorizada. In: DEL RIO, Vicente; OLIVEIRA, Lívia (Org.). Percepção ambiental: A experiência brasileira. 2 ed.. São Paulo: Studio Nobel/Universidade Federal de São Carlos, 1999.

MATOS, Karenina Cardoso. A paisagem das águas: A percepção dos usuários como subsídios para elaboração de diretrizes urbanísticas para as margens dos rios Poti e Parnaíba e seu entorno (Teresina-PI). 2004. Dissertação (Mestrado em Arquitetura e Urbanismo) - Faculdade de Arquitetura e Urbanismo, Universidade Federal do Rio de Grande do Norte, Natal, 2004

SÁ CARNEIRO, Ana Rita; MESQUITA, Liana de Barros. Espaços livres do Recife. Recife: Prefeitura da cidade do Recife/ Universidade Federal de Pernambuco, 2000.

TUAN, Ti-Fu. Topofilia. Um estudo da percepção, atitudes e valores do meio ambiente. São Paulo, 1980. 